\title{
Pharmaceutical management of bone catabolism: the bisphosphonates
}

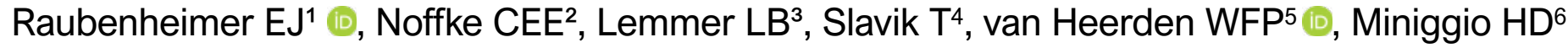 \\ 1 MChD, PhD, DSc; Ampath Histopathology Laboratory, Pretoria, Department of Oral Pathology and Oral Biology, University of Pretoria, South Africa, \\ OMFS IMPATH, Katholieke Universiteit Leuven, Belgium \\ 2 MSc; OMFS IMPATH, Katholieke Universiteit Leuven, Belgium \\ 3 MBChB, M Prax Med, M Med (Path), FCFP (SA); Ampath Histopathology Laboratory, Pretoria, South Africa \\ MBChB, MMed(Anat Path); Ampath Histopathology Laboratory, Pretoria, South Africa \\ $5 \mathrm{MChD}, \mathrm{PhD}, \mathrm{DSc}$; Department of Oral Pathology and Oral Biology, University of Pretoria, Pretoria, South Africa \\ 6 BDS, MScMed (Bioethics and Health Law); Faculty of Health Sciences, Sefako Makgatho Health Sciences University, Pretoria, South Africa
}

Corresponding author: Prof EJ Raubenheimer, Ampath Histopathology Laboratory, Pretoria, South Africa; tel: +27 870870176; cell: +27 829082788; email:ejraub@fox5.co.za and raubenheimere@ampath.co.za

\begin{abstract}
Background: Conditions associated with catabolism of bone are common and progress sub-clinically with devastating skeletal consequences. Over the past two decades, bisphosphonates have become increasingly popular for the preventative management of the skeleton in these conditions.

Methods: Recent literature pertaining to the mechanisms of action, clinical indications and complications of bisphosphonate therapy was retrieved using Google Scholar and Pubmed.

Aims of study: To provide an overview of the mechanisms of action, indications, contraindications and complications of the bisphosphonates available for clinical use in South Africa.

Results: Despite the availability of alternative management regimens, bisphosphonates remain the pharmaceuticals of choice for the management of hypercalcaemia and generalised catabolic skeletal disorders such as osteoporosis, skeletal metastatic disease, Paget's disease of bone, glucocorticoid bone disease and osteogenesis imperfecta. Although adverse complications such as tachycardia, bowel and oesophageal irritation, pain, jawbone necrosis and atypical femur fractures are well documented, information remains limited on the long-term effects of bisphosphonate therapy on skeletal health. This manuscript provides an update on the mechanisms of action, principles applied to the selection of the most appropriate management regimen, monitoring of the response and complications of the bisphosphonates marketed in South Africa.
\end{abstract}

Level of evidence: Level 5

Key words: bisphosphonates, osteoporosis, bone metastases, Paget's disease of bone, glucocorticoid bone disease, osteogenesis imperfecta, jaw bone necrosis

Citation: Raubenheimer EJ, Noffke CEE, Lemmer LB, Slavik T, van Heerden WFP, Miniggio HD. Pharmaceutical management of bone catabolism: the bisphosphonates SA Orthop J 2019;18(1):47-52. http://dx.doi.org/10.17159/2309-8309/2019/v18n1a6

Editor: Dr Franz Birkholtz, Walk-A-Mile Centre for Advanced Orthopaedics, Pretoria, South Africa

Received: June 2018

Accepted: August 2018

Published: March 2019

Copyright: () 2019 Raubenheimer EJ. This is an open-access article distributed under the terms of the Creative Commons Attribution Licence, which permits unrestricted use, distribution and reproduction in any medium, provided the original author and source are credited.

Funding: The authors received no funding from any agency in the public or commercial domain before or during the preparation of the manuscript.

Conflict of interest: The authors have no direct or indirect association with any of the companies manufacturing any of the pharmaceuticals or products reflected in the manuscript. 


\section{Introduction}

Despite the development of innovative pharmaceuticals and autoantibodies for the manipulation of skeletal metabolism (reviewed elsewhere ${ }^{1}$ ), bisphosphonates (BPs) remain the first-line choice for the management of hypercalcaemia and several systemic catabolic skeletal disease states. BPs are derived from natural occurring pyrophosphates, which due to their calcium-binding properties, have been used for more than a century to soften water. Research performed by Procter and Gamble in the early 1960s on the prevention of dental caries and calculus deposits on teeth, ${ }^{2,3}$ exposed their affinity for bone and subsequent incorporation in the skeleton. It has subsequently been shown that approximately one-third of BPs absorbed are incorporated in the skeleton where they may persist lifelong. The remainder are cleared by the kidney without being further metabolised. ${ }^{4}$ During bone resorption, the incorporated BPs are released where they exert a profound local influence on the cellular components of the bone metabolic unit (BMU) and in particular the osteoclasts (readers are referred to Raubenheimer et al. ${ }^{5}$ for more information on bone remodelling). These discoveries prompted pharmaceutical companies to manipulate the basic pyrophosphate structure of BP, and several patented drugs with different pharmacokinetics and clinical applications became available in a potentially lucrative market.

The purpose of this review is to highlight the mechanisms of action, clinical applications and complications of the BPs available in South Africa. ${ }^{6}$

\section{Mechanisms of action}

\section{First generation BPs}

The early non-nitrogen-containing BPs, also referred to as the first generation BPs (Table I), promote osteoclast apoptosis through incorporation in adenosine triphosphate (ATP). The nonhydrolysable state of the modified ATP results in neutralisation of several enzymatic processes of the osteoclast which ultimately culminate in osteoclast apoptosis, thereby effectively reducing resorptive activity. 2,7 The calcium-binding capacity of the first generation BPs, which retard mineralisation activity, is an outstanding characteristic which is enhanced by their resistance to neutralisation by alkaline phosphatase. This unique property is the reason for their specific clinical application.

Table I: Commercially available first generation BPs ${ }^{6}$

\begin{tabular}{|l|l|c|l|}
\hline $\begin{array}{c}\text { Active } \\
\text { ingredient }\end{array}$ & $\begin{array}{c}\text { Route of } \\
\text { administration }\end{array}$ & Potency* & \multicolumn{1}{|c|}{ Trade name } \\
\hline Clodronate & Oral & 10 & Bonefos \\
\hline Etidronate & Oral \& IV & 1 & $\begin{array}{l}\text { Didronel } \\
\text { (not listed in SA**) }\end{array}$ \\
\hline Tiludronate & Oral & 10 & $\begin{array}{l}\text { Skelid } \\
\text { (not listed in SA) }\end{array}$ \\
\hline
\end{tabular}

*Potency of osteoclast inhibition is relative to etidronate which is empirically set at $1^{8}$

**Delivery molecule for $(99 \mathrm{~m})$ Tc-based radiopharmaceuticals for skeletal imaging

\section{Clinical applications of first generation BPS}

Due to the retardation of mineralising activity and binding of calcium, first generation BPs are not suited for the treatment of osteoporosis. ${ }^{2,3}$ Indications for their use are restricted to the management of hypercalcaemia which is commonly associated with disseminated skeletal malignancies and as an adjunct to the management of osteolysis resulting from bone metastases of malignant tumours.
During administration (either through the oral or intravenous route) the patient should be monitored for hypocalcaemia and secondary hyperparathyroidism as the drug tends to chelate blood calcium (the reason for its efficiency in correcting hypercalcaemia of malignancy). Furthermore, due to the chelating property, ingestion with milk or if the intravenous (IV) route is followed, with calciumcontaining solutions like Ringer's, is contraindicated. Similar to the second and third generation BPs, it should be used with caution in patients with impairment of renal functions, and regular renal function tests are advised before and during the course of therapy. Most of the other precautions and complications of BP therapy, which are discussed later, also apply to the first generation BPs. For more detail on the schedule of administration, drug interactions, complications and contraindications readers are referred to the manufacturers' recommendations.

\section{Second and third generation BPS}

The second and third generation BPs, also known as the nitrogencontaining BPs, were developed by adding a nitrogen side chain to the pyrophosphate molecule. This addition increases the efficiency of osteoclast inhibition significantly. Various other modifications to the nitrogen-containing backbone contributed to the development of several commercially available BPs with differing potencies (Table II). Their method of action differs from first generation BPs. Nitrogen-containing BPs bind to a key enzyme in the pathway critical for cytoplasmic stress fibre assembly and membrane ruffling ${ }^{9}$ and, due to the subsequent osteoclast inhibition, apoptosis is induced. ${ }^{10}$ The effects are not restricted to osteoclasts only. Although their actions on other cells are less clear, they are known to exert a strong anti-apoptotic influence on the osteoblast lineage and therefore play a role in preserving the vitality of bone-forming cells. ${ }^{11,12}$ Unlike first generation BPs, these characteristics make second and third generation BPs most appropriate for the preservation of bone in catabolic skeletal disease.

Table II: Commercially available second- and third generation $\mathrm{BPs}^{6}$

\begin{tabular}{|c|c|c|c|}
\hline $\begin{array}{c}\text { Active } \\
\text { ingredient }\end{array}$ & $\begin{array}{c}\text { Route of } \\
\text { administration }\end{array}$ & Potency* & Trade name \\
\hline $\begin{array}{l}\text { Alendronic } \\
\text { acid }\end{array}$ & Oral & 500 & $\begin{array}{l}\text { Accord Alendronate, } \\
\text { Alendronate } \\
\text { Unicorn, Aldren, } \\
\text { Boniran, Densate, } \\
\text { Fosagen, Fosavance, } \\
\text { Fosamax, Femax, } \\
\text { Osteonate, Osteobon, } \\
\text { Ran-alendronate, } \\
\text { Sandoz Alendronate }\end{array}$ \\
\hline Risedronate & Oral & 2000 & Actamax, Actonel \\
\hline Ibandronate & Oral \& IV & 1000 & Boniva \\
\hline $\begin{array}{l}\text { Zoledronic } \\
\text { acid }\end{array}$ & IV & 10000 & $\begin{array}{l}\text { Zomatron, Zolapor, } \\
\text { Zometa, Zobone, } \\
\text { Aclasta, Zolon, Zoclasta } \\
\text { and others }\end{array}$ \\
\hline Pamidronate & IV & 100 & Aredia \\
\hline
\end{tabular}

${ }^{*}$ Potency of osteoclast inhibition relative to etidronate which is empirically set at $1^{8}$

\section{Clinical applications of second and third generation BPs}

\section{Osteoporosis}

Pharmaceutical intervention in osteoporosis must always be complemented by lifestyle and dietary measures which include weight-bearing exercise, cholecalciferol administration to patients 
with low vitamin D concentrations, and calcium supplementation. The latter is mandatory if the daily calcium intake is below 700 mg. ${ }^{7,13}$ Alendronic acid and risedronate are the BPs of choice in the majority of men and women with osteoporosis. In cases with poor drug compliance or intolerance to oral BPs, the IV route or the use of non-BP regimens such as denosumab, raloxifene or hormone replacement therapy could be considered. Several authors reported on the administration of BPs in conjunction with other pharmacological agents (for a synopsis see Drake et al..$\left.^{7}\right)$. The combination of initial PTH treatment (teriparatide) with maintenance BP therapy seems to provide the strongest anabolic effect on the skeleton. ${ }^{14,15}$

Due to their hydrophilic nature, BPs are poorly absorbed from the gastrointestinal tract. ${ }^{16}$ This is the reason why BPs administered intravenously are significantly more effective than those administered via the oral route. Although the recent availability of BPs allowing once weekly (alendronic acid and risedronate) and even once monthly (risedronate and ibandronate) administration has overcome the disadvantage of poor patient compliance associated with daily regimens, the IV route eliminates the gastrointestinal adverse effects experienced by some patients on oral BPs. IV preparations (zoledronic acid, ibandronate, pamidronate) require even less frequent administration but suffer the disadvantage of potentially inducing an acute phase reaction, kidney damage and a higher frequency of osteonecrosis of the jaw than reported with the oral route (see later). The significance of patient compliance should not be underestimated as current evidence suggests that observance of the therapeutic regimen rather than the type of BP used, is of prime importance in minimising fracture risk. ${ }^{17}$

Although there are no recommendations on the monitoring of therapy beyond ten years, treatment review should be performed regularly (at least after three years with IV BPs and five years with oral $\mathrm{BPs}) .^{13}$ In treated individuals, reassessment of fracture risk can be performed using FRAX with femoral head bone mineral density (BMD). ${ }^{18}$ Short-term non-invasive monitoring of response to therapy is the ideal, and the use of molecular markers for bone metabolism are subsequently gaining momentum. The release of 3-hydroxypyridinium cross links of collagen pyridinoline and deoxypyridinoline during bone resorption can be quantified in blood and urine by high-performance liquid chromatography (HPLC). Provided a baseline is established on a patient, a decrease can be interpreted as response to therapy. The two components show a high specificity for bone, are not taken up from food, and although variables resulting from volume distribution and metabolic clearance are as yet exploratory, their concentrations are currently viewed as the most appropriate indicators of bone resorption. ${ }^{19}$

Discontinuation of administration is advised in high-risk fracture patients who have been treated with alendronate, risedronate and zoledronic acid for longer than five years. In low-risk fracture patients a 'drug holiday' is recommended after one to two years for risedronate, three to five years for alendronate and three to six years for zoledronic acid. ${ }^{20}$

Duration of the skeletal-protective action of BPs is related to the potency of the BP used, dosage of administration, metabolism and clearance of the drug. Although the determination of the effective half-life is hampered by technical challenges, it has been suggested that after one IV administration, alendronate has a half-life of more than ten years. ${ }^{21}$

\section{Malignancies affecting the skeleton}

The skeletal morbidity of myeloma is related to osteoclast-induced bone resorption with associated pain and hypercalcaemia. In a consensus statement of the Mayo Clinic Myeloma Group, IV pamidronate is recommended as the drug of choice for the management of these morbidities as pamidronate effectively suspends bone resorption, alleviates bone pain and corrects hypercalcaemia. Pamidronate is perceived to have a lower risk for inducing jaw osteonecrosis than the alternative, zoledronic acid. ${ }^{22}$ Upon remission, treatment is discontinued after two years. If remission is not achieved, pamidronate administration should be considered every three months at a reduced dosage.

In a recent update of 18 trials reporting on 4843 men with advanced prostate cancer, BP therapy was shown to decrease the number of skeletal events and reduce disease progression. ${ }^{23}$ Although non-opioid and opioid analgesics are employed to manage metastatic bone pain, BPs can offer added pain reduction. ${ }^{24}$ A joint review drafted by an expert panel of Cancer Care Ontario and the American Society of Clinical Oncology suggests that BP administration reduces bone recurrence and improves survival of postmenopausal patients with non-metastatic breast cancer. ${ }^{25}$ In separate studies, a substantial relief of the skeletal complications and pain have been demonstrated in patients with breast cancer receiving IV BPs. ${ }^{26,27}$ Of the oral BPs, only daily administration of ibandronate has been shown to be beneficial. The skeletal protecting action of BPs is advantageous particularly to women receiving oestrogen ablation therapy for hormone-sensitive breast cancer. $^{28}$

\section{Other clinical applications}

Paget's disease of bone is characterised by an increase of bone resorption followed by defective bone formation. These processes result in a weak skeleton, deformities, skull enlargement and pain. BPs suppress bone resorption with subsequent normalisation of serum alkaline phosphatase concentrations and are therefore recommended for the management of the active and symptomatic phase of the condition. ${ }^{7} \mathrm{~A}$ recent practice guideline confirms that oral risedronate, pamidronate and IV zoledronic acid are effective in this regard. BP therapy however does not eradicate the radiological changes, nor does it improve the deformities or reduce pain resulting from the associated osteoarthritis. ${ }^{29}$

With present data available, BP therapy holds potential for the improvement of the quality of life of children with osteogenesis imperfecta. IV administration of pamidronate results in a significant increase in cortical bone thickness and trabecular bone volume. ${ }^{30}$ Success has also been reported with oral alendronate in the management of the consequences of this devastating genetic disease. ${ }^{31}$ Although the mechanism of action is not clear, it appears that the inhibition of osteoclast- induced resorption augments the defective process of bone formation. Although the use of BPs in children is cautioned against, ${ }^{7}$ the net clinical benefit of BP administration to children suffering osteogenesis imperfecta may outweigh its potential disadvantages.

Glucocorticoid therapy is the most important cause for pharmaceutically induced osteoporosis. Glucocorticoids induce skeletal catabolism which is the result of induction of apoptosis of cells of the osteoblast lineage and activation of bone resorption through prolonging the lifespan of osteoclasts. ${ }^{32}$ Patients taking $2.5 \mathrm{mg}$ or more prednisone per day for three months or longer and with a high risk for fractures can benefit from BP administration which should start at the onset of glucocorticoid therapy. Risedronate and alendronic acid are first choices and where these drugs are contraindicated, second line agents such as denosumab or teriparatide could be considered. ${ }^{33}$ Because of limited information on the advantages BP intervention in patients taking glucocorticoids, the American College of Rheumatology advises vitamin $\mathrm{D}$ and calcium supplementation without BP administration in patients with a low fracture risk. ${ }^{34}$

Pamidronate and alendronic acid have been shown to reduce the markers of bone resorption during skeletal immobilisation 
and their protective influence on the skeleton, and reduction of hypercalcaemia and nephrolithiasis is promising. ${ }^{35,36}$ Management of the skeletal morbidity of paediatric conditions such as anorexia, juvenile rheumatoid arthritis and cystic fibrosis is awaiting data of long-term studies on whether the net benefit outweighs the potential complications. The embedding of modifications of BPs on implants creating bioactive surfaces which facilitate bio-integration and reduce implant failure will certainly gain momentum in the future.

\section{Adverse effects}

Despite considerable attention given to BP-related osteonecrosis of the jaw $(\mathrm{ONJ})$, this complication is rare in patients receiving oral BPs: ONJ occurs in between $0.1 \%$ of myeloma patients and $5 \%$ of advanced prostate cancer patients on BPs. ${ }^{37,38}$ The majority of cases with ONJ were described in patients receiving high doses of IV BPs for myeloma and breast cancer (for a summary see Drake, et $a{ }^{7}{ }^{7}$ ). The occurrence of $\mathrm{ONJ}$ is also related to the anti-angiogenic properties of the BP administered, ${ }^{39,40}$ host factors which include the presence of dormant jawbone infections and the efficiency of the immune response. ${ }^{41} \mathrm{~A}$ variety of infective agents are implicated, including Actinomyces-like organisms and fungi. It is important to clear all foci of potential jaw bone sepsis before commencement of BP therapy and delay invasive dental surgery in patients receiving the medication. Patients with chronic ear infections may likewise develop osteonecrosis of the external auditory canal. ${ }^{42}$ Thigh, hip or groin pain should alert clinicians to another rare and not yet fully understood complication, namely atypical femur fracture. ${ }^{43}$

An acute phase reaction is experienced by nearly a quarter of patients receiving the first IV dose of nitrogen-containing BP, and the incidence thereafter decreases progressively with each administration. ${ }^{44}$ This reaction is characterised by pyrexia with concomitant headache, arthralgia, myalgia and influenza-like symptoms, and pre-treatment with histamine receptor antagonists, antipyretics or corticosteroids may provide relief. ${ }^{1}$ An increase in serious atrial fibrillation (requiring hospitalisation) was reported in patients receiving IV zoledronic acid. ${ }^{44}$ Although verifiable data is not yet available for the other BPs, the risk appears to be smaller, if not negligible. ${ }^{7}$ This complication is an indication for considering one of the non-BP skeletal cytokine modulators or auto-antibodies in the management regimen (summarised elsewhere ${ }^{1}$ ).

Oesophageal irritation and erosions are common in patients on oral BPs. Patients should be advised to swallow the BP with a full glass of water and remain in an upright position for one hour after ingestion. Avoid taking anti-acid drugs containing aluminium or magnesium due to the danger of chelating and neutralising the BP. Gastro-oesophageal irritation has not been reported with the IV route which is recommended in patients with uncontrollable oesophageal discomfort.

Renal function can rapidly deteriorate in patients on IV BPs particularly if the creatinine clearance and glomerular filtration rates are below $30 \mathrm{ml} / \mathrm{min}^{32,33}$ and $35 \mathrm{ml} / \mathrm{min}$. respectively. 13,45,46 The oral route of administration may be appropriate in patients with mild renal impairment ${ }^{7}$ or alternatively a cytokine modulator or autoantibody could be considered as second line regimen. Concomitant use of non-steroidal anti-inflammatory drugs increases the potential for peptic ulcers ${ }^{47}$ and renal dysfunction ${ }^{46}$ and is contraindicated.

Severe incapacitating musculoskeletal pain, distinct from the acute phase symptoms, has been reported in a small number of patients receiving alendronate and risedronate. ${ }^{48}$ The risk factors for this complication are unknown. IV administration may precipitate hypocalcaemia particularly in patients with a substantial skeletal tumour burden, Paget's disease, hypoparathyroidism, compromised renal function and hypovitaminosis D. ${ }^{49-51}$ In order to minimise the risk of hypocalcaemia, albumin-corrected serum calcium concentrations should be determined and corrected before commencing with IV infusion of BPs. ${ }^{7}$ If unresponsive, consider an alternate management regimen. ${ }^{1}$ Conjunctivitis, uveitis, episcleritis and scleritis are rare complications of both oral and IV BPs. The incidence is less than $0.1 \%$, appears to be limited to patients receiving risedronate, and resolves within weeks of discontinuation of therapy. ${ }^{48}$ Administration of BPs is contraindicated during pregnancy, lactation and in patients manifesting with allergic-type reactions against the drug.

\section{Conclusion}

The therapeutic roll-out of BPs for the management of generalised skeletal anabolism gained momentum over the past decade. Although the benefits of BP therapy outweigh the risks in several progressive skeletal anabolic states, the lack of long-term studies on large patient samples is hampering the generation of accurate data on the advantages and complication of BP therapy in some of the less common conditions. The long-term effects on the skeleton in particular will be interesting as the repair of micro-fractures, which contribute to skeletal strength, is impaired.

\section{Ethics statement}

The authors upheld the principles of non-maleficence and an accurate reflection of the literature during the preparation of the synopsis.

\section{Declaration}

The authors declare authorship of this article and that they have followed sound scientific research practice during the preparation thereof. This research is original and does not transgress plagiarism policies.

\section{Acknowledgements}

Gratitude is expressed towards the Ampath Histopathology Laboratory, the Catholic University of Leuven and the University of Pretoria for providing support in the preparation of the manuscript.

\section{Author contributions}

All the authors were involved in the collection of relevant information from the literature. REJ compiled the manuscript from the data received and all authors contributed to the revision of the manuscript and the final preparation of the submitted copy.

\section{ORCID}

Raubenheimer EJ (D) https://orcid.org/000-003-0554-2398 van Heerden WFP (iD http://orcid.org/0000-0003-2494-667X

\section{References}

1. Raubenheimer EJ, Miniggio HD, Lemmer LB, Slavik T, van Heerden WFP. Recent advances in the pharmaceutical manipulation of bone remodelling: the quest for a healthy skeleton. SA Orthop J 2018;17(1):55-60.

2. Russell RG. Bisphosphonates: from bench to bedside. Ann NY Acad Sci 2006;1068:367-401.

3. Francis MD, Valent DJ. Histo rical perspectives on the clinical development of bisphosphonates in the treatment of bone diseases. J Musculoskelet Neuronal Interact 2007;7(1):2-8.

4. Fleisch H. Pharmaconetics. In: Bisphosphonates in bone disease: from the laboratory to the patient. University of Berne, Berne, Switzerland 1993p.50

5. Raubenheimer E, Miniggio H, Lemmer L, van Heerden W. The role of bone remodelling in maintaining and restoring bone health: an overview. Clinic Rev Bone Miner Metab 2017;15:90-97.

6. Snyman JR (ed.). Monthly index of medical specialties. MIMS 2016;56:90-94.

7. Drake MT, Clarke BL, Khosla S. Bisphosphonates: Mechanism of action and role in clinical practice. Mayo Clin Proc 2008;83(9):1032-45. 
8. Dunford JE, Thompson K, Coxon FP, Luckman SP, Hahn FM, Poulter D, Ebetino FH, Rogers MJ. Structure-activity relationships for inhibition of farnesyl diphosphate synthase in vitro and inhibition of bone resorption in vivo by nitrogen-containing bisphosphonates. J Pharmacol Exp Ther 2001;296:235-42.

9. Hall A. Rho GTPases and the actin cytoskeleton. Science 1998;5350:509-14.

10. Luckman SP, Hughes DE, Coxon FP, Graham R, Russel G, Rogers MJ. Nitrogen-containing bisphosphonates inhibit the mevalonate pathway and prevent post-translational phenylation of GTP-binding proteins, including RAS. J Bone Miner Res 1998;13:581-89.

11. Plotkin LI, Lezcano V, Thostenson J, Weinstein RS, Manolagas SC, Bellido T. Connexin 43 is required for the anti-apoptotic effect of bisphosphonated on osteocytes and osteoblasts in vivo. $J$ Bone Miner Res 2008;23:1712-21.

12. Bellido T, Plotkin LI. Novel actions of bisphosphonates in bone: preservation of osteoblast and osteocyte viability. Bone 2008;49:50-55.

13. Compston J, Cooper A, Gregson C, Hewitt S, Reid D, Selby P, Thompson F, Thurston A, Vine N, Kanis J. UK clinical guideline for the prevention and treatment of osteoporosis. Arch Osteoporosis 2017;12:1-22.

14. Kurland ES, Heller SL, Diamond B, MacMahon DJ, Cosman F, Bilezikian JP. The importance of bisphosphonate therapy in maintaining bone mass in men after therapy with teriparatide [human parathyroid hormone (1-34)]. Osteoporos Int 2004;15:992-97.

15. Black DM, Bilezikian JP, Ensrud KE, Greenspan SL, Palermo L, Hue T, Lang TF, McGowan JA, Rosen CJ. PaTH study investigators. One year of alendronate after one year of parathyroid hormone (1-84) for osteoporosis. N Engl J Med 2005;353:555-56.

16. Lin JH. Bisphosphonates: a review of their pharmacokinetic properties. Bone 1996;18:75-85.

17. Siris ES, Harris ST, Rosen CJ, Barr CE, Arvesen JN, Abbott TA, Silverman $\mathrm{S}$. Adherence to bisphosphonate therapy and fracture rates in osteoporotic women: relationship to vertebral and nonvertebral fractures from 2 US claims databases. Mayo Clin Proc 2006;81:1013-22.

18. Leslie WD, Lix LM, Johansson $H$, Oden A, McCloskey E, Kanis JA. Manitoba bone density program. Does osteoporosis therapy invalidate FRAX for fracture prediction? J Bone Miner Res 2012;27:1243-51.

19. Seibel MJ. Biochemical markers of bone turnover: Part I: Biochemistry and variability. Clin Biochem Rev 2005;26:97-122.

20. Anagnostis P, Pashou SA, Mintziori G, Ceausu I, Depyere H, Lambrinoudaki I, Mueck I, Perez-lopez FR, Rees M, Senturk LM, Simoncini T, Stevenson JC, Stute P, Tremollieres FA, Goulis DG. Drug holidays from bisphosphonates and denosumab in postmenopausal osteoporosis: EMAS position statement. Maturitas 2017;101:23-30.

21. Khan SA, Kanis JA, Vasikaran S, Kline WF, Matuszewski BK, McClosey EV, Beneton MN, Getz BJ, Scribberas DG, Hollard SD, Orgee J, Coombs GM, Rogers SR, Porras AG. Elimination and biochemical responses to intravenous alendronate in postmenopausal osteoporosis. J Bone Miner Res 1997;12:1700-1707.

22. Lacey $M Q$, Dispenzieri A, Gertz MA, Greipp PR, Gollbach $\mathrm{KL}$, Hayman SR, Kumar S, Lust JA, Raikumar SV, Russel SJ, Witzig TE, Zeldenrust SR, Dingli $D$, Bergsagel PL, Fonseca $R$, Reeder CB, Stewart AK, Roy V, Dalton RJ, Carr AB, Kademan D, Keller EE, Viozzi CF, Kyle RA. Consensus statement for the use of bisphosphonates in multiple myeloma. Myo Clin Proc 2006;81:1047-53.

23. Macherey S, Monsef I, Jahn F, Jordan K, Yuen KK, Heidenreich A, Skoetz N. Bisphosphonates for advanced prostate cancer Cochrane Database Syst Rev 2017;12:CD006250. Doi: 10.1002/14651858.CD006250.pub2.

24. von Moos R, Costa L, Ripamonti Cl, Niepel D, Santini D. Improving quality of life in patients with advanced cancer: Targeting metastatic bone pain. Eur J Cancer 2017;71:80-94.

25. Dhesy-Thind S, Fletcher GG, Blanchette PS, Clemons MJ, Dillmon MS, Frank ES, Gandhi S, Gupta R, Mates M, Moy B, Vandenberg T, Van Poznak $\mathrm{CH}$. Use of adjuvant bisphosphonates and other bone modifying agents in breast cancer: a cancer care Ontario and
American Society of Clinical Oncology clinical practice guideline. $J$ Clin Oncol 2017;35:2062-81.

26. Clemons MJ, Dranitsaris G, Ooi WS, Yogendran G, Sukovic T, Wong BY, Verma S, Pritchard KI, Trudeau M, Cole DE. Phase II trial evaluating the palliative benefit of second-line zoledronic acid in breast cancer patients with either a skeletal-related event or progressive bone metastases despite first-line bisphosphonate therapy. J Clin Oncol 2006;24;4895-4900.

27. Body JJ, Diel IJ, Lichinister MR. MF 4265 Study Group. Intravenous ibandronate reduces the incidence of skeletal complications in patients with breast cancer and bone metastases. Ann Oncol 2003;14:1399-1405.

28. Gnant MF, Mlineritsch B, Luschin-Ebengreuth G, Grampp S, Kaessmann H, Schmid M, Menzel C, Piswanger-Soelkner JC, Galid A, Mittlboeck M, Hausmaninger H, Jakes Z. Zoledronic acid prevents cancer treatment-induced bone loss in premenopausal women receiving adjuvant endocrine therapy for hormoneresponsive breast cancer: a report from the Austrian Breast and Colorectal Cancer Study Group. J Clin Oncol 2007;25:820-28.

29. Singer FR, Bone HG, Hosking DJ, Lykes KW, Murad MH, Reid $\mathrm{RI}$, Siris ES. Paget's disease of bone: an endocrinological society clinical practice guideline. J Clin Endocrinol Metab 2014;99:4408-22.

30. Rauch F, Travers R, Plotkin H, Glorieux FH. The effects of intravenous pamidronate on bone tissue of children and adolescents with osteogenesis imperfecta. J Clin Invest 2002;110:1293-99.

31. DiMeglio LA, Peacock M. Two-year clinical trial of oral alendronate versus intravenous pamidronate in children with osteogenesis imperfecta. J Bone Miner Res 2006;21:132-40.

32. Mitra R. Adverse effects of corticosteroids on bone metabolism: a review. PM R 2011;3:466-71.

33. Hsu E, Nanes M. Advances in treatment of glucocorticoidinduced osteoporosis. Curr Opin Endocrinol Diabetes Obes 2017:24:411-17.

34. Buckley L, Guyatt G, Fink HA, Cannon M, Grossman J, Hansen KE, Humphrey MB, Lane NE, Magrey M, Miller M, Morrison L, Rao M, Robinson $A B$, Saha S, Wolver S, Bannuru RR, Vaysbrot E, Osani M, Turgunbaev M, Miller AS, McAlindon T. 2017 American College of Rheumatology guideline for the prevention and treatment of glucocorticoid-induced osteoporosis. Arthritis Rheumatol 2017;69:1521-37.

35. Nance PW, Schryvers O, Leslie W, Ludwig S, Krahn J, Ubelhart D. Intravenous pamidronate attenuates bone density loss after acute spinal chord injury. Arch Phys Med Rehabil 1999;80:243-51.

36. Gilchrist NL, Frampton CM, Ackland RH, Nicholls MG, March RL, Maguire P, Heard A, Reilly P, Marshall K. Alendronate prevents bone loss in patients with acute spinal chord injury: a randomized, double-blind, placebo-controlled study. J Clin Endocrinol Metab 2007;92:1385-90.

37. Mhaskar R, Kumar A, Miladinovic B, Djulbegovic B. Bisphosphonates in multiple myeloma: an update network meta-analysis. Cochrane Database Syst Rev 2017;12:CD003188. DOI:10.1002/14651858.CD003188.pub4.

38. Hayes AR, Brungs D, Pavlakis N. Osteoclast inhibitors to prevent bone metastases in men with high-risk, non-metastatic prostate cancer: A systematic review and meta-analysis. PLoS One 2018;13:e0191455. DOI:10.1371/journal.pone.0191455. eCollection2018.

39. Wood J, Bonjean K, Ruetz S, Bellahcène A, Devy L, Foidart JM, Castronovo V, Green JR. Novel antiangiogenic effects of the bisphosphonate compound zoledronic acid. J Pharmacol Exper Ther 2002;302;1055-61.

40. Sharma D, Ivanovski S. Bisphosphonate related osteonecrosis of the jaw (BRONJ): diagnostic criteria and possible pathogenic mechanisms of an unexpected anti-angiogenic side effect. Vascular Cell 2013;5:1.

41. Kumar V, Sinha RK. Bisphosphonate related osteonecrosis of the jaw: an update. J Maxillofac Oral Surg 2014;13:386-93.

42. Thorsteinsson A-L, Lomholt A, Eiken P. Bisphosphonate-induced osteonecrosis of the external auditory canal: a case report. $J$ Clin Med Case Reports 2015;2:3

43. Saita $Y$, Ishijima M, Kaneko K. Atypical femoral fractures and bisphosphonate use: current evidence and clinical implications. Ther Adv Chronic Dis 2015;6:185-93. 
44. Black DM, Delmas PD, Eastell R, Reid IR, Boonen S, Cauley JA Cosman F, Lakatos P, Leung PC, Man Z, Mautalen C, Mesenbrink $\mathrm{P}$, Hu H, Caminis J, Tong K, Rosario-Jansen T, Krasnow J, Hue TF, Sellmeyer D, Eriksen EF, Cummings SR. Once-yearly zoledronic acid for treatment of postmenopausal osteoporosis. N Engl J Med 2007;356:1809-22.

45. Smetana S, Michilin A, Roseman E, Biro A, Boaz M, Katzir Z. Pamidronate-induced nephrotoxic tubular necrosis- a case report. Clin Nephrol 2004;61:63-67.

46. Chang JT, Green L, Beitz J. Renal failure with use of zoledronic acid (letter). N Engl J Med 2003;349:1676-79.

47. Miyake K, Kusunoki M, Shinji Y, Shindo T, Kawagoe T, Futagami S, Gudis K, Tsukui T, Nakajima A, Sakamoto C. Biphosphonate increases risk of gastroduodenal ulcer in rheumatoid arthritis patients on long-term nonsteroidal antiinflammatory drug therapy. $J$ Gastroenterol 2009;44(2):113-20.

48. Wysowski DK, Chang JT. Alendronate and risedronate: reports of severe bone, joint and muscle pain (letter). Arch Internal Med 2005;165:346-47.

49. Jones SG, Dolan G, Lengyel K, Myers B. Severe increase in creatinine with hypocalcaemia in thalidomide-treated myeloma patients receiving zoledronic acid infusions (letter). $\mathrm{Br} J$ Haematol 2002;119:576-77.

50. Mishra A, Wong L, Jonklaas J. Prolonged symptomatic hypocalcaemia with pamidronate administration and subclinical hypoparathyroidism. Endocrine 2002;14:159-64.

51. Maalouf NM, Heller HJ, Odiva CV, Kim PJ, Sakhahee K. Bisphosphonate-induced hypocalcaemia: report of 3 cases and review of the literature. Endocrine Pract 2006;12:48-53. 